\title{
Lyle Fearnley, Virulent zones: animal disease and global health at China's pandemic epicenter
}

\author{
Durham, London, Duke University Press, 2020, 280 p.
}

\author{
Muriel Figuié ${ }^{1,2}$
}

Accepted: 31 January 2022 / Published online: 14 February 2022

(c) INRAE and Springer-Verlag France SAS, part of Springer Nature 2022

The ongoing COVID-19 pandemic has raised various questions about the emergence of new viruses. These include the geographic source of the virus at the origin of the pandemic, countries' compliance with international global health standards (e.g. standards related to sharing epidemiological information), and the role of traditional local cultures (e.g. the sale of wild species in wet markets). These debates are paving the way to a geography of blame that is denounced by many anthropologists. In his book "Virulent Zones", Lyle Fearnley offers a pertinent analysis of a previous pandemic, the highly pathogenic influenza HPAI H5N1 that played a major role in the construction of global health governance in the 2000s. As with COVID19, the HPAI H5N1 pandemic focused the world's attention on China as the source of the pandemic and raised similar issues of potential antagonism between national sovereignty and global health. In hindsight and based on an in-depth ethnographic approach, the author offers a rich and nuanced perspective of the process of pointing to China as a "virulent zone".

The main topic of this book is the concept of a "pandemic epicentre". The author investigates how scientists working on influenza have progressively broadened their focus on the genetics of viruses to include the search for the source (in terms of space and species) of new viruses; how this search has created new "working landscapes" that have displaced scientists out of their laboratories and into the field; how China has been singled out as the epicentre of new influenza viruses; and how a geopolitical diplomacy has emerged to access strategic epidemiological data and material originating from this epicentre.

The first section of the book traces the history of the science of influenza, from virology to spatial ecology. It began in the 1930 s with the ability to isolate viruses,

Muriel Figuié

muriel.figuie@cirad.fr

1 CIRAD, UMR MoISA, 34398 Montpellier, France

2 Univ Montpellier, CIHEAM-IAMM, CIRAD, INRAE, Institut Agro, IRD, Montpellier, France 
and influenza's definition as a viral disease. From then onwards, a virological approach to influenza was developed in laboratories, contributing to the development of standardised international norms for isolating, categorising, and naming the various influenza viruses. With the discovery of the zoonotic origins of influenza in the 1950s, the virus-centred approach evolved towards a "laboratory ecology" studying the contribution of animals (wild and domestic) in the virus' circulation. Later on came the understanding of the role of animals (e.g. birds and pigs), not only as reservoirs for pathogens but also as active vessels of virus recombinations and reassortments. Researchers' attention turned to the phylogeny of viruses and to species' interactions. International programmes for the prevention of new influenza epidemics were developed aiming to monitor at their source new viruses that could emerge from animals in order to contain them before they jump to human beings and cause epidemics. This monitoring revealed the wide diversity of influenza viruses present in southern China's duck population, leading researchers (namely Shortridge and Stuart-Harris) to identify the area as the ecological epicentre of influenza pandemics in the 1980s. As a consequence, the ecology of influenza turned into a spatial ecology, with China as the principal epidemiological landscape.

In the second section of the book, Fearnley analyses the consequences of the displacement of influenza research from virology to spatial ecology. This displacement brought researchers to Poyang Lake in southern China, where a wide range of influenza viruses was found, raising the question of why influenza viruses emerge here, and how? Leaving their laboratories, researchers explored new "working landscapes" where the frontiers between wild and domestic spaces are blurred and where local stakeholders have their own experience and knowledge of the epidemic. In Poyang Lake, a natural reserve for migrating birds borders with large duck farms that have multiplied over recent decades; farmers experience regular outbreaks in duck populations so dealing with "vital uncertainties" has become part of their daily farming practice. Outside their labs, experts renewed their research into the potential drivers of emerging viruses, building new hypotheses based on a spatial ecology. This displacement into the field helped focus attention not only on biological drivers but also on social ones such as the functioning of the different duck farming systems (and their interface with the "wilderness"), the veterinary profession's capacity to address the challenges raised by the "livestock revolution", and the increasing longdistance trade of farmed animals connecting markets and different countries, etc. This shift also drew experts' attention to other sources of knowledge such as that of farmers - sources whose access depends on experts' affinities with the rural world.

In the third section, the author investigates the geopolitical consequences of this displacement. The ecological landscape of influenza is also a political one. With the H5N1 epidemic, international organisations such as the WHO and FAO pointed to China as an epicentre of influenza viruses where the prevention of potential new pandemics should focus, based on monitoring and containing viruses at their source. The FAO's decision to set up an Emergency Center of Transboundary Animal Diseases (ECTAD) in China was an attempt by the organisation to get closer to the source of new zoonotic viruses as they "moved expertise into the epicentre, and virus samples, genome sequences and research data out" (p 136). By conducting an ethnographic study at the ECTAD in China following the 
day-to-day work of its director Dr. Vincent Martin, Fearnley analyses the strategies developed by Dr. Martin to build a global health diplomacy and to tackle the Chinese authorities' reluctance to share epidemiological information and material. This was a two-fold strategy to cultivate networks of social and professional affinities with Chinese ministry officials, technical experts, and veterinarians on the one hand, and to separate the ecological truth from political interests on the other.

With these three sections, the book's principal contribution is to move beyond simplistic and dualistic views and to give nuance to the commonly accepted divisions between the categories of wild and domestic animals, lab and field research, national and international expertise, specialist and lay knowledge, and sovereignty and the global good. Surprisingly for a medical anthropologist, the author focuses on the animal dimension of influenza (agricultural authorities, farmers and veterinarians, birds and the quest to identify the host species), and pays little attention to the human dimension (medical authorities, patients and doctors, the quest to identify "Patient Zero") and the interactions between the two sectors. Studying the interactions (cooperation and competition) in the epicentre between international organisations (e.g. FAO, OIE, and WHO) as well as bilateral cooperation (e.g. competition between different countries to access viral material in China) could also have helped give nuance to the international/national and sovereignty/global health divides. For example, the case of H5N1 in neighbouring Vietnam, studied by different authors (Figuié, Guenel, Porter, Scoones, Tuong, etc.) illustrates how H5N1 has led to rivalry between national and provincial authorities and between the Vietnamese Communist Party and the various ministries, and how any "One Health" issue (engaging the human, animal, and environmental sectors) is not only a challenge in terms of multilevel governance, but also a multisectoral challenge.

In his conclusion, Fearnley summarises the two main models that support current investigations into influenza: the dominant risk model focuses on the areas and species where new viruses are more likely to emerge, following the concept of an epicentre and "the heroic figure of the virus hunter". This approach contributes to support the construction of large surveillance webs and data-sharing platforms. The second model, the global suitability model (exemplified by the research conducted by epidemiologist Marius Gilbert), is based on a more systemic and multidisciplinary approach; it addresses the factors of vulnerability, including biological and anthropogenic factors, that favour the propagation of new viruses. This model is used to support prevention measures to reduce vulnerability to new viruses.

This book represents a major contribution to the analysis of current dominant vision of pandemic preparedness focusing on the biological dynamics of new viruses, and targeting their geographic containment and eradication. With the H5N1 pandemic, the author describes how experts were confronted with the social factors of emergence and vulnerability, and with the stratification between the epidemiological and the political spaces. This is not new. As an example, the concept of emerging infectious diseases (EID) devised in the 1990s (Lederberg et al., 1992) had already focused on anthropogenic factors (such as environmental changes and the industrialisation of animal husbandry) that contribute to creating "new viral routes" conducive to the transmission of pathogens between human beings and wild or domestic animals. Interestingly, Fearnley has been able to use the status of FAO expert in medical 
anthropology to follow how the concept of emerging diseases reconfigures experts' daily working practices.

The "Chinese pangolin fever", the name initially given to COVID-19 in some parts of the world, confirms the attention paid to the search for the pandemic's origin, in species and in spaces, as highlighted by Fearnley with H5N1. However, public debate on COVID-19 also shows that infectious diseases and pandemics have joined the category of "industrial risks" (e.g. nuclear and chemical pollution) as a product of modernity, as defined by Beck (2009/2007). New infectious diseases do not have their origins in a "nature" external to society; they are man-made and mark the end of "natural risks". Addressing these risks requires far more than surveillance. These risks challenge our development model and the related vulnerabilities. Their anticipation requires deep structural changes that can only be designed through a socio-political process. As global risks, they "create chains of interlocking political decisions and outcomes among states and their citizens, which alter the nature and dynamics of territorially defined governance systems" (Beck \& Grande, 2010). However, they also require the creation of new relationships with non-human entities for a renewed approach to health that goes beyond the ideal of disease eradication and biosecurity.

New infectious diseases represent a rich topic for social sciences: "Emerging diseases are sources of instability, uncertainty and even crises that can make visible features of the social order ordinarily opaque to investigation" (Dingwall et al., 2013). However, Fearnley's book shows that emerging diseases not only provide a lens through which to study the social order, but are also a subject in their own right. His analysis goes beyond a classic medical anthropology approach; he navigates between different areas and topics of social studies (sciences, expertise, international relations, rurality, etc.) to forge alliances between different fields of knowledge, and to work across the classic divisions. This is crucial to address the complexity of emerging diseases. Despite this complexity, let us hope that this book will help motivate other social scientists to grasp this challenging subject.

N.B. Open access to this book in pdf form is available at: https://library.oapen. org/handle/20.500.12657/48499

\section{References}

Beck U. (2009/2007) World at risk. Polity Press.

Beck U. \& Grande E. (2010) Varieties of second modernity: The cosmopolitan turn in social and political theory and research. British Journal of Sociology, 61(3), 409-443.

Dingwall R., Hoffman L. M. \& Staniland K. (2013) Introduction: Why a sociology of pandemics? Sociology of Health \& Illness, 35(2), 167-173.

Lederberg J., Shope R. E., Oaks S. C. J. \& Institute of Medicine (US), Committee on Emerging Microbial Threats to Health, (Eds.). (1992). Emerging infections: Microbial threats to health in the United States. New York.

Publisher's Note Springer Nature remains neutral with regard to jurisdictional claims in published maps and institutional affiliations. 